\title{
A TECHNIQUE FOR DETERMINING THE YEAR OF THE OUTSIDE RING OF DEAD TREES ${ }^{1}$ BY ARTHUR W. GHENT ${ }^{2}$
}

\author{
INTRODUCTION
}

Studies recently initiated in the Black Sturgeon Lake area of Ontario required the development of a technique whereby the year of the outside ring of dead trees might be determined. It is convenient to consider this outside ring as representing the year of death of the tree, an assumption which will be correct in many instances. However, a tree killed by an early spring fire before growth is initiated provides one instance when the assumption would be incorrect.

Various techniques have been employed in other forest ecological problems to assign dates to the rings of dead trees. For the most part these techniques are based on the presence of a marker ring of unusual size, or on the rating of prominent growth rings as larger or smaller than average. The author and associates attempted to apply these techniques to dead trembling aspen, Populus tremuloides Michx., and found them frequently uncertain. Many trees had undergone forty or more years of suppressed growth prior to death, during which period none of the rings were noticeably more prominent than others. Different personnel engaged in the work had difficulty duplicating each other's results, and were left with no satisfactory way of assessing the reliability of the results obtained.

A comparison of the agreement between measurements of the growth rings on living and dead trees has been adopted as the most satisfactory technique. To some extent the methods used parallel those employed in critical archaeological research involving ring analysis of wooden remnants, such as structural timbers. As an example of the degree of accuracy obtained, it was possible to establish that at least some of the trees reported killed by a recent insect outbreak had been standing dead and unnoticed for two or three years before the outbreak began.

Dendrochronologists have surmounted the problems of tree vigor under varying circumstances of age, site, and suppression with often quite complex adjustments to their measurements. To the forest ecologist, interested in reconstructing a year by year mortality distribution for a large sample of trees, such adjustments are impractical. To replace these adjustments, a simple contingency test has been developed which allows the raw measurements from living and dead trees to be analysed for agreement. This test provides at least an index of the confidence which can be placed in the year selected visually as the best fit, and allows unbiased discrimination should several plausible points of fit present themselves.

The author wishes to express his gratitude to the many associates who have assisted either with the field work or with the development of the techniques outlined in this paper, particularly J. R. Rooke. The helpful criticism of M. L. Prebble, R. M. Belyea, W. G. Wellington, and G. Stehr, all of the Division of Forest Biology; G. B. Oakland, Head, Statistical Research and Service Unit, Science Service, Ottawa; and L. Butler, Professor of Genetics

\footnotetext{
1 Contribution No. 69, Division of Forest Biology. Science Service, Department of Agriculture,

2 Forest Insect Laboratory, Sault Ste. Marie, Ontario, Canada.
} 
and Statistics, Department of Zoology, University of Toronto is especially appreciated.

\section{METHOD}

Year dates or ring numbers are assigned to all discernible rings in discs cut from living and dead trees, respectively. Increment cores are less desirable, but can also be used. Ring widths are measured by means of an ocular micrometer attached to a binocular dissecting microscope. Using a magnification of $7.5 \mathrm{X}$, ring widths can be measured with this equipment to an accuracy of about \pm .005 cms. Measurements so obtained are plotted as frequency polygons.

Graphs for individual dead trees are aligned with a graph depicting the average measurements from a series of living trees, and a position of apparent best fit selected. Should this position be correct, the last year of growth for the dead tree can be read directly from the graph for living trees as the year opposite the dead tree's outer ring.

Collection and preparation of material

For the preparation of average graphs, discs should be cut from vigorous living trees of the same species and, where possible, from the same stands as the dead trees which are the object of study. When there is heart rot at stump height, a more complete record of the growth is sometimes found at a point four or five feet from the ground. Studies made on trembling aspen at Black Sturgeon Lake showed little difference in the growth pattern along the main trunk, except within the early rings laid down when the crown was still local to that portion of the trunk.

Fallen dead trees may rot in a few years, except where supported clear of the ground by other windfalls or similar obstructions. Such dry sound wood in fallen trunks has allowed convincing dating of trembling aspen 25 years after death.

To attain an accurate growth assessment, measurements from three radii chiselled into each disc appear adequate. Empirical tests indicated that between 90 and 95 per cent of the actual growth trends of trembling aspen are accurately depicted by the average of three radii.

Before measurements are made, it is desirable to establish that the same actual ring has been assigned the same year or ring number on all three radii. An excellent check is provided when rings can be counted directly to the core. When the core is obscured by rot, a prominent ring close to the core can be followed in a channel chiselled concentric with the growth rings, and established as common to all three radii. A second prominent ring followed in the same manner provides a check against compensating errors. A final check is provided by plotting the measurements obtained from the three radii one above the other. Major fluctuations generally agree if the three radii are properly dated.

When measuring discs from dead trees which have begun to rot, it has been found advantageous to saw the disc into wedges. These wedges can be cleared of saw marks along the transverse edges with a sharp knife or razor blade. Working along the edges permits more delicate slicing with less tendency to obscure the growth rings by brooming the fibres. For checking the dating between radii, prominent rings can be traced from one wedge to 


\section{DETERMINING YEAR OF OUTSIDE RING-GHENT}

the other by matching the cleared edges under the microscope. To facilitate the dating of badly deteriorated wood, the individual wedges can be placed for a half hour in a bath of hot paraffin. Sufficient penetration is obtained to reinforce weak spots which might otherwise break down during preparation.

Discrepancies in ring numbers between radii on discs cut from dead trees can often be traced to incomplete outside rings. It is often advisable to follow the outside rings around the disc before the remaining rings are assigned numbers.

Rings obscured by discoloration show clearly when viewed by transmitted light. Whole radii can be dated and measured by preparing temporary slides of thin overlapping slices removed with a sharp chisel. Radii treated in this manner can be tied in to the other radii both at the core, and by comparison of the plotted measurements.

Increment cores are less desirable than discs for ring measurement. No check is available on the accuracy of the dating, or on incomplete rings in the years just prior to death. However, two or three cores can be taken from different angles at approximately the same height in the tree, and each dated and measured with as much care as possible. If discrepancies between the plotted measurements are noted, appropriate points on the cores can be checked for missed rings, or for streaks of parenchymatous tissue or stains falsely selected as the end of a growing season. Little extra time is required to take two or three additional short cores as a check on the peripheral rings.

Selection of the point of best fit

Inevitably it is the major fluctuations in growth which catch the eye, and between which agreement is most convincing. These are also least likely to vary from one tree to the next. At the same time even minute differences between years recur with surprising consistency, and provide the basis for the proposed method of assessing the goodness of fit.

Dead trees can be divided into two classes based on the appearance of their plotted measurements. The first consists of trees showing vigorous growth fluctuations until a few years prior to death, comparable in magnitude to those of dominant living trees. For these, agreement at one point is usually so marked that no other possibility can be entertained. In this class death is often traceable to such factors as fire, severe insect defoliation, or windfall, which may kill trees more or less independently of vigor.

The second class consists of trees showing severely suppressed growth for many years prior to death. During this period few or none of the fluctuations found in healthy living trees may be reflected in an eye-catching manner. Graphs for dead trembling aspens No. 2 and No. 6 in Fig. 1 illustrate this class.

Trees in the second class, and a few in the first class which are difficult to date convincingly because of recurring growth patterns, require a statistical method of assessing the goodness of fit of the points selected. The method developed can be applied so quickly that it provides a convenient means of indicating the reliability of the year selected, even when there is no reason to doubt the accuracy of visual alignment of the graphs. 
Testing the goodness of fit

Three techniques were investigated in the development of an adequate method of testing the goodness of fit. The first involved testing ring measurements from dead trees directly against those from living trees, after proportional adjustments to equalize total measurements within the period of overlap. The second technique involved rating each point on the graphs as a plus, minus, or zero when each ring thus represented was greater than, less than, or equal to the ring laid down in the previous year, and after discarding disagreement with zero ratings, assessing the goodness of fit in a $2 \times 2$ contingency test.

Although the second method is suitable in many cases, the same difficulty kept both procedures from being consistently applicable. Plotted measurements from trees of declining vigor show a tendency to slope downwards with time. For this reason measurements cannot be tested directly without complex adjustments to tilt the axis of the graph, or to re-express all measurements as ratios of a central trend line. This same downward slope leads to an excess of minus ratings when the second technique is used. When the total of the available variates does not exceed 60 to 70 , this excess of minus ratings effectively disturbs the sensitivity of the $2 \times 2$ contingency test.

The general structure of the plus-minus technique seemed promising since it proved adequate for trees showing no general tendency to decline in growth. It was only necessary to devise some system or ratings that would be independent of long term growth trends superimposed on the ring size fluctuation by the vigor of the tree. This problem has been solved with apparent satisfaction by rating the turn taken by the graph at each point, instead of rating the position of the point itself.

Viewing the graph lengthwise as if looking from the outside ring in towards the core, each point, with the exception of the first and last, can be rated as a right, left or zero as the graph turns to the right, to the left, or continues straight ahead. Again the agreement between these ratings assigned to the graphs of living and dead trees is assessed in a $2 \times 2$ contingency test. Approximately the same number of rights as lefts occur despite any tendencies for the graphs to rise or fall. As a result all four expected values are usually much the same, and the maximum sensitivity is obtained from the low numbers of variates available for testing. A right or left on one graph opposite a zero on the other is discarded. The alternative is to distribute relatively few variates among the nine cells of a $3 \times 3$ table, leaving many cells empty or nearly so, and artificially magnifying the chi-square achieved. Agreement between two zeros, however, is very sensitive, and the few extra variates thus acquired can be assigned to the rigbt-right or the left-left cell by any rule of thumb placing them without consistent bias.

This system expresses in one rating the relationship between the size of a given ring, and the size of the rings laid down in both the preceding and the following years. It is for this reason that the right-left system of ratings allows growth trends from suppressed trees, showing only as increased or decreased rates of declining growth, to be compared directly with more vigorous fluctuations. Absolute magnitudes of the rings are not directly involved in the 
test. The basis of the test is the strong agreement which can be found at one point of alignment of two time series having much the same internal organization of these ring size relationships. This test can be formulated as a hypothesis that the apparent agreement at the point selected is explainable as a coincidence of a few prominent growth trends, and that the overall agreement does not exceed that which could be expected from purely random alignment of the two time series.

When measurements from a large sample of living trees are available, it is possible to test for the significance of the year to year trends. Numerical values can be assigned to indicate the strength of the right or left turn, and treating these as differences between paired values, a $t$ test can be used to assess the significance of the average trend for each year. The relatively large error component tolerated by the $2 \times 2$ contingency test makes it doubtful if this time consuming task is justified. In Fig. 1 a straight average of the measurements from living trees has been accepted as the true reflection of the growth trends.

\section{Discussion}

This technique is offered as one seemingly well suited to many of the requirements of forest ecological research. The methods have been applied successfully by the author and associates working with material from trembling aspen, Populus tremuloides Michx., balsam fir, Abies balsamea (L.) Mill., sugar maple, Acer saccbarum Marsh., and white spruce, Picea glauca (Moench) Voss. No difficulties are anticipated with related species, although some difficulty may be found in accurately delimiting the growth rings of certain ring-porous hardwoods.

In Fig. 1 three groups of graphs are presented as illustrations of the results obtained. Stand No. 1 is a 130 -year-old stand of trembling aspen near Black Sturgeon Lake, Ontario. For space considerations, only the outer 85 years of the graph for living trees has been shown. The open triangle opposite the year 1881 on this graph indicates a suspected outbreak of the forest tent caterpillar, Malacosoma disstria $\mathrm{Hbn}$. Solid triangles above recent points in Fig. 1 indicate suppression periods which coincide with known periods of forest tent caterpillar defoliation. No attempt is made in this paper to assess the influence of forest tent caterpillar defoliation on mortality.

Stand No. 2 in Fig. 1 is a younger stand of trembling aspen, approximately 70 years old, also near Black Sturgeon Lake. The top graph in this group represents the average of measurements from ten living trees. Immediately below this, for comparison, is the graph for one of these ten trees. No important differences are to be found in any of the major fluctuations.

Stand No. 3 in Fig. 1 is a 65-year-old stand of sugar maple from the Parry Sound District of Ontario. These graphs were prepared from increment cores, by the methods outlined previously in this paper.

Table I gives the probability values obtained by testing each of the dead trees from Fig. 1 by the right-left contingency test at both the visual best fit, and at the next best fit obtainable within sensible limits. These limits were imposed by the age and origin of the stand and by the year in which the discs 


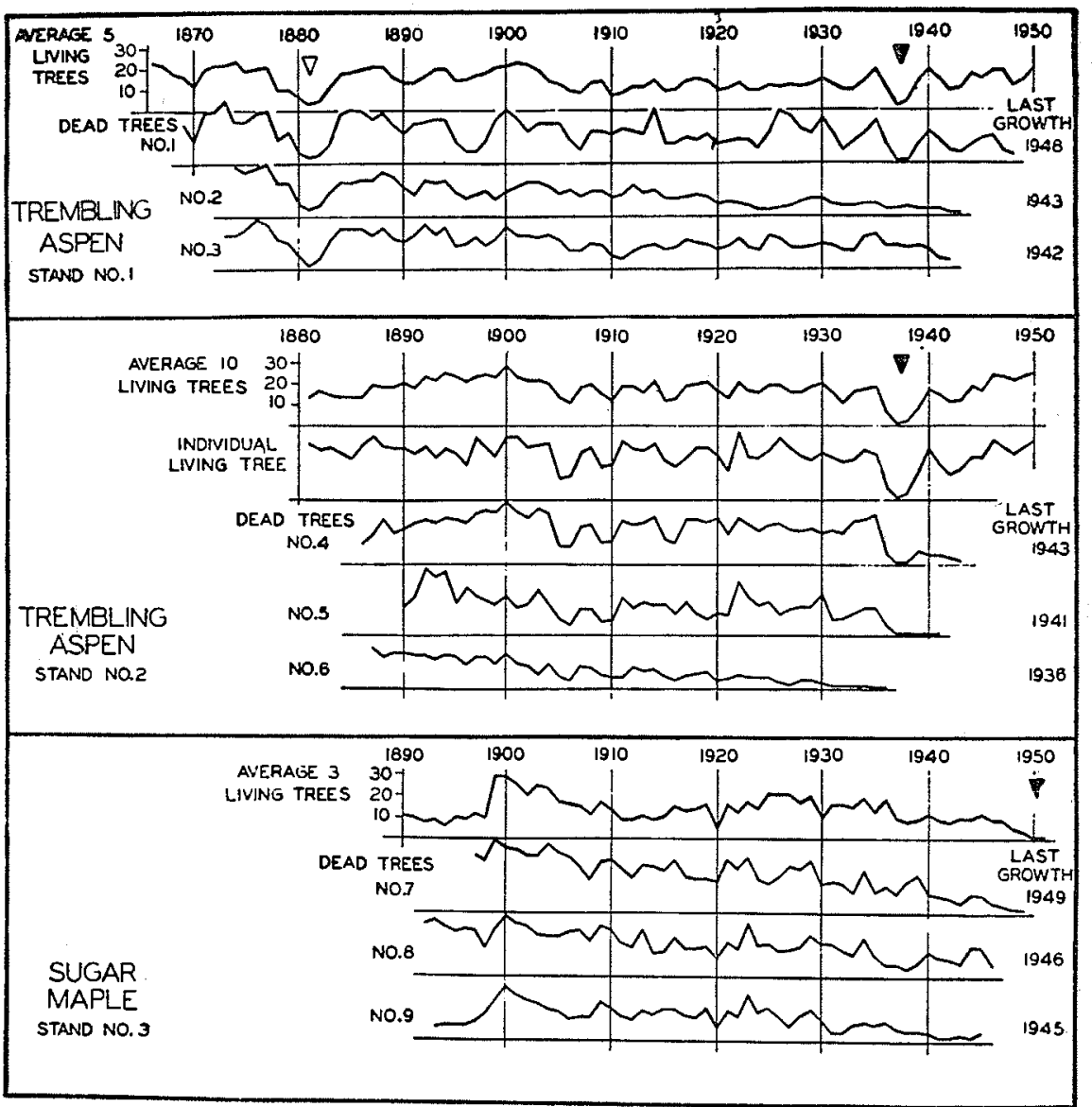

FIGURE 1: Typical results obtained in three stands. Stand No. 1, Black Sturgeon Lake, Ontario, 130-year-old trembling aspen; stand No. 2, Black Sturgeon Lake, 70-year-old trembling aspen; stand No. 3, Parry Sound District, Ontario, 65-year-old sugar maple. Giraphs of dead trees are aligned with those of living trees at the points of vistal best fit. Solid triangles indicate suppression periods which coincide with known periods of forest tent caterpillar defoliation. Open triangle opposite 1881 in the top graph indicates a suspected forest tent caterpillar outbreals. All graphs are plotted in unconverted micrometer units, indicated by the vertical scale to the left of each average graph for living trees. Ten micrometer units equal approximately one millimetre.

were taken from dead trees. Probability values are rarely beyond the 5 per cent level at the next best fit. Dead trees No. 4, No. 5, and No. 6 from Stand No. 2 have been tested not only against the average graph for living trees, (test A), but also against the individual living tree plotted in Fig. 1, (test $B$ ), and against two other living trees from the same sample, (tests C and D). $V$ isual alignment yields the same year as the best fit for each tree in all four cases, and the contingency test discriminates in every instance between this year of visual best fit and the next best fit obtainable. The year of the next 


\section{TABLE I}

\begin{tabular}{|c|c|c|c|c|c|}
\hline $\begin{array}{l}\text { Dead } \\
\text { tree no. }\end{array}$ & Compared with & $\begin{array}{l}\text { Visual } \\
\text { best fit }\end{array}$ & $\begin{array}{c}\text { Probability } \\
\text { of "chance" } \\
\text { fit }\end{array}$ & $\begin{array}{c}\text { Next best } \\
\text { fit obtain- } \\
\text { able }\end{array}$ & $\begin{array}{c}\text { Probability } \\
\text { of "chance" } \\
\text { fit }\end{array}$ \\
\hline \multicolumn{6}{|c|}{ Stand No. 1} \\
\hline 1 & average of five & 1948 & .0002 & 1943 & .08 \\
\hline 2 & living trees & 1943 & .01 & 1938 & .14 \\
\hline 3 & & 1942 & .0005 & 1947 & .03 \\
\hline \multicolumn{6}{|c|}{ Stand No. 2} \\
\hline \multirow{4}{*}{4} & test $\mathrm{A}$ & 1943 & .0005 & 1940 & .17 \\
\hline & test $B$ & 1943 & .002 & 1940 & .17 \\
\hline & test $\mathrm{C}$ & 1943 & .02 & 1933 & .18 \\
\hline & test $D$ & 1943 & .006 & 1948 & .17 \\
\hline \multirow{4}{*}{5} & test $A$ & 1941 & .008 & 1933 & .19 \\
\hline & test $\mathrm{B}$ & 1941 & .03 & 1933 & .20 \\
\hline & test $C$ & 1941 & .05 & 1949 & .08 \\
\hline & test D & 1941 & .007 & 1933 & .05 \\
\hline \multirow{4}{*}{6} & test $A$ & 1936 & .0004 & 1941 & .09 \\
\hline & test B & 1936 & .01 & 1933 & .09 \\
\hline & test $\mathrm{C}$ & 1936 & .0003 & 1941 & .17 \\
\hline & test $\mathrm{D}$ & 1936 & .03 & 1941 & .07 \\
\hline \multicolumn{6}{|c|}{ Stand No. 3} \\
\hline 7 & average of three & 1949 & .0007 & 1936 & .03 \\
\hline 8 & living trees & 1946 & .001 & 1940 & .08 \\
\hline 9 & & 1945 & .004 & 1951 & .02 \\
\hline
\end{tabular}

TABLE I: Comparison of the probability values derived by testing the nine dead trees from Fig. 1 at the visual best fit and at the next best fit obtainable, with the right-left contingency test. Dead trees from stand No. 2 (Nos, 4, 5, and 6) are shown tested against (A) the average of ten living trees, $(B)$ the individual living tree plotted in Fig. 1 , (C) a second, and (D) a third individual living tree from the same sample, but not plotted in Fig. 1

best fit is variable. By hypothesis the agreement at the next best fit is at the level of a chance assortment, and minor variations in the graph for living trees will award this position first to one year and then another.

Fig. 2 illustrates the fluctuation in chi-squares obtained by testing the goodness of fit of dead trees No. 2, No. 6, and No. 7 from Fig. 1, at all points within sensible limits regardless of the visual agreement. Since the expected values for the diagonally opposite cells of a $2 \times 2$ contingency table must always deviate in the same direction from the observed values, it is possible to classify each contingency distribution as being either in the direction of agreement or disagreement. Fluctuations for dead trees No. 6 and No. 7 become violent about the point of best fit, dropping to significant disagreement to the right or left of this point. When this happens it confirms the argument that the agreement at the point of best fit is not a chance assortment, but the correct alignment of two time series involving much the same internal 


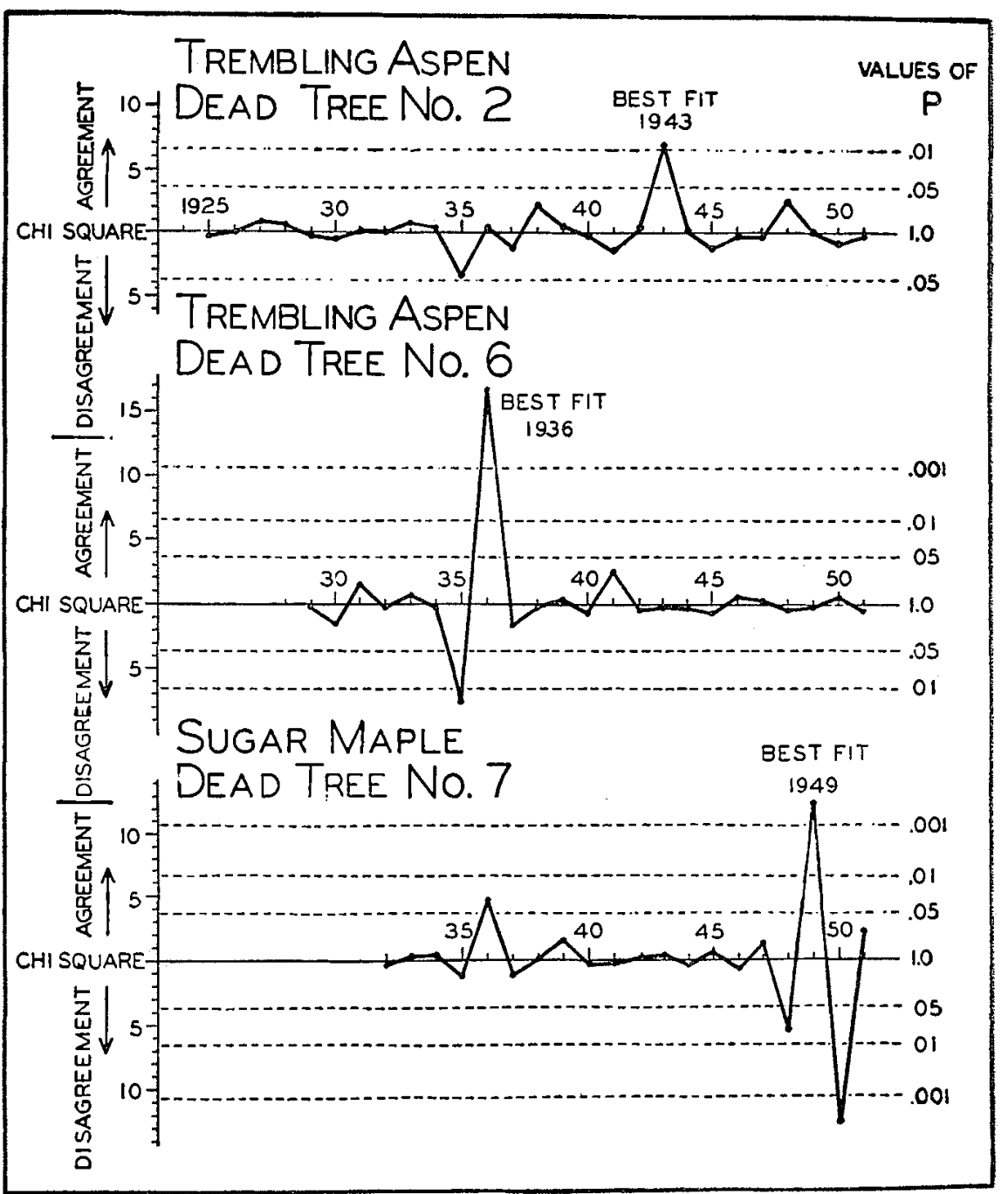

FIGURE 2: Fluctuations in chi-squares obtained by testing one tree from each of the three groups pictured in Fig. 1 by the right-left contingency test at all points within sensible limits regardless of the visual agreement.

organization. Displaced one year either way from the point of best fit, a maximum number of points are brought into disagreement, sometimes to as strongly signficant a level as the agreement at the point of best fit. However, less jagged growth curves tending more to long sweeping trends, such as No. 2, Fig. 1, often show a gradual improvement in the goodness of fit from either side of the point of best fit. 
Data for Table I and Fig. 2 were obtained by means of a punch card technique which allowed a rapid survey of all the possible contingency distributions which could be set up for a given pair of time series. Extremely low probability values given for some of the points of best fit are approximations derived by graphical extrapolation from standard chi-square tables. Yate's correction for continuity has been used throughout. These probability values are of interest however only in a relative sense, since the method of testing is an approximation based on the direction of the trends without regard for their magnitude.

\section{SUMMARY}

A method is proposed whereby the year of the outside ring of dead trees can be determined by visual inspection of the agreement between plotted ring measurements from living and dead trees. Rings are measured with an ocular micrometer attached to a binocular dissecting microscope. Methods are suggested whereby the accuracy of the dating of growth rings can be checked.

Where the technique leaves a choice between several points of fit, a test has been devised which allows probability values to be assigned to the points selected. These probability values are indicative of the confidence which can be placed in the year selected, and allow unbiased discrimination between several plausible years. Looking lengthwise along the graph from the outside ring in towards the core, each point is rated as a right or left with respect to the turn taken by the graph. A comparison of the agreement between these ratings on living and dead trees is suited to the $2 \times 2$ contingency test with Yate's correction for continuity.

This technique has allowed determination of the year of the outside ring on dead trembling-aspen trees to a low probability of etror 25 years after this last ring was laid down. Graphical and tabular material is presented to illustrate the agreement between ring width measurements made on living and dead trees, and to illustrate the manner in which the contingency test discriminates between the year of best fit and other plausible points of fit which might be selected. 